\title{
Exact solutions and experimental research for continuous triple- equal- span fully profiled sandwich panels
}

\author{
Dimitrios Moutaftsis*1, Martin D. Heywood ${ }^{1}$, Raymond G. Ogden ${ }^{1}$ \\ ${ }^{1}$ Oxford Brookes University, Faculty of Technology, Design and Environment, Oxford, UK. \\ *Corresponding author.
}

\begin{abstract}
The paper presents a set of newly developed exact analytical solutions for triple- equal- span arrangements of panels with fully profiled faces in flexure. Their derivation was based on a set of general fundamental equations retrieved from the governing differential equations for sandwich beams. Specifically designed tests of single- and triple-span fully profiled panels with steel faces (outer fully profiled and inner lightly profiled) and polyisocyanurate cores were conducted to investigate the response with regards to stiffness and initial failure, which are critical for serviceability limit states. Good agreement between test and theory was demonstrated, with safe results in all cases. The new design method permits the elimination of a significant amount of conservatism compared to current methods.
\end{abstract}

\section{Keywords}

Sandwich panels; Composite panels; Fully profiled faces; Structural testing; Global static analysis; Design method

\section{List of symbols}

\begin{tabular}{|l|l|l|l|}
\hline$A_{c}$ & Area of lightweight core & $M_{F 2}$ & $\begin{array}{l}\text { Bending moment in 'flange' part - steel face } \\
(2)\end{array}$ \\
\hline$A_{F 1}$ & Area of steel face (1) & $\mathrm{N}_{\mathrm{F} 1}$ & Axial force in steel face (1) \\
\hline $\mathrm{A}_{\mathrm{F} 2}$ & Area of steel face (2) & $\mathrm{M}_{\mathrm{S}}$ & Bending moment in "sandwich" part \\
\hline $\mathrm{B}$ & Bending stiffness & $\mathrm{N}_{\mathrm{F} 2}$ & Axial force in steel face (2) \\
\hline $\mathrm{B}_{\mathrm{D}}$ & Bending stiffness of 'flange' part & $\mathrm{P}$ & Point load applied at span \\
\hline $\mathrm{B}_{\mathrm{S}}$ & Bending stiffness of 'sandwich' part & $\mathrm{q}$ & Uniformly distributed load on the panel \\
\hline $\mathrm{d}_{\mathrm{C}}$ & Clear core depth & $\mathrm{V}_{\mathrm{F} 1}$ & Shear force in steel face (1) \\
\hline $\mathrm{d}_{2}$ & Depth of outer profile & $\mathrm{V}_{\mathrm{F} 2}$ & Shear force in steel face (2) \\
\hline
\end{tabular}




\begin{tabular}{|l|l|l|l|}
\hline$d_{11}$ & Position of outer profile's neutral axis & $V_{\mathrm{S}}$ & Shear force in core \\
\hline$d_{21}$ & Position of inner profile's neutral axis & W & Total applied load in one span \\
\hline $\mathrm{e}$ & Distance between centroids of faces & $\alpha$ & Parameter \\
\hline $\mathrm{E}_{\mathrm{F} 1}$ & Young's modulus for steel face (1) & $\beta$ & Parameter \\
\hline $\mathrm{E}_{\mathrm{F} 2}$ & Young's modulus for steel face (2) & $\delta$ & Deflection \\
\hline $\mathrm{G}_{\mathrm{C}}$ & Shear modulus of the core & & $\begin{array}{l}\text { Location of applied load within the panel } \\
\text { (ratio between 'distance of applied point load } \\
\text { from panel end' and 'length of panel') }\end{array}$ \\
\hline $\mathrm{G}_{\mathrm{eff}}$ & Effective shear modulus of the core & $\varepsilon_{\mathrm{i}}$ & Parameter of stress distribution \\
\hline $\mathrm{I}_{\mathrm{F} 1}$ & Moment of inertia of steel face (1) & $\lambda$ & Parameter \\
\hline $\mathrm{I}_{\mathrm{F} 2}$ & Moment of inertia of steel face (2) & $\xi$ & $\begin{array}{l}\text { Location within the panel (ratio between } \\
\text { 'distance panel end' and 'length of panel') }\end{array}$ \\
\hline $\mathrm{L}$ & Span of the panel & $\sigma_{\mathrm{Fij}}$ & Axial stress in the steel sheet \\
\hline $\mathrm{M}_{\mathrm{sup}}$ & Applied bending moment at the support & $\tau_{\mathrm{C}}$ & Shear stress in the core \\
\hline $\mathrm{M}_{\mathrm{D}}$ & Bending moment in 'flange' part & $\tau_{\mathrm{Fi}}$ & Shear stress in the steel sheet \\
\hline $\mathrm{M}_{\mathrm{F} 1}$ & $\begin{array}{l}\text { Bending moment in 'flange' part - steel face } \\
(1)\end{array}$ & $\mathrm{x}$ & Coordinate along the longitudinal axis \\
\hline
\end{tabular}

\section{Introduction}

Sandwich panels represent a form of lightweight composite construction, comprising a rigid layer of insulation between and adhered to two thin layers of metal sheeting, forming a single manufactured unit. The system benefits from a high strength-to-weight ratio, good structural and thermal performance, rapid speeds of production (up to $12 \mathrm{~m} / \mathrm{min}$ ), and good air-tightness characteristics. They are also relatively simple to handle and install, have good durability and offer many architectural possibilities. The market for sandwich panels is large and wellestablished both in relation to roof and wall applications.

The metal faces are typically made of steel with a thickness range between $0.3 \mathrm{~mm}$ and $0.7 \mathrm{~mm}$, or less commonly aluminium. Face geometry can be flat, micro-ribbed (often referred to as 'satinlined'), lightly profiled or fully profiled. Roof applications typically comprise a fully profiled external sheet and a lightly profiled internal (liner) sheet, while wall applications mostly comprise flat, lightly profiled or micro-ribbed geometries. The core is typically made of Polyisocyanurate (PIR), Polyurethane (PUR), Extruded Polysterene (EPS) or Mineral Wool (slabs or lamellas). In the UK, PIR and Mineral Wool are the most extensively used sandwich panel core materials, with the latter being used primarily for wall applications. 
Sandwich panels may be installed as single-, double- or multi-span arrangements. Multi-span continuous panels are increasingly popular, particularly for roof applications, due to the greater efficiency of manufacturing, transport and installation (fewer parts to handle). They are also superior to single- and double-span panels in terms of structural performance and air-tightness.

In the UK, design calculations for sandwich panels are typically produced by manufacturers and presented in the form of load versus equal-span tables for single-, double- and multi- span arrangements. Triple-span arrangements are used as sufficiently representative of multi-span conditions. For fully profiled panels, while exact analytical design solutions are available for both single- and double- span arrangements with equal spans under distributed load (ECCS Recommendations [1]), there is a lack of guidance for triple- and multi-span cases. Established finite element modelling methods (Davies [2], [3]) are accurate and virtually applicable for any case, however they require significant computational effort and specialist knowledge, whilst currently available approximate solutions provide conservative results to ensure safety (Heywood et. al. [4], Berner [5]). This observation has been made from the analysis of a large number of structural tests for commercial purposes by the authors. While discrepancies between theory and practice may often be due to the reliability of material properties, they also reflect the approximations implicit in existing theory (Berner [5], ECCS Recommendations [1], Heywood et. al. [4]). This is particularly acute for continuous arrangements.

Accurate quantification of exact bending moments and stress distribution across continuous sandwich panels is very important for design and specification. Typically working load failures occur at intermediate support locations where maximum bending moments are developed. Reliable global analysis is therefore particularly beneficial.

The aim of this paper is to present and validate a set of reliable exact analytical solutions for bending problems of continuous triple-span fully profiled sandwich panels with equal spans. 
The developed solutions can then be used by designers and specifiers to accurately estimate the distribution of bending moments and stresses by incorporating them into conventional computer tools such as spreadsheets, without the need for specialist software. The focus is on the design of sandwich panels with one face fully profiled and one lightly profiled, i.e. systems used primarily (but not exclusively) for roof applications.

\section{Literature review of bending problems' solutions development}

The structural performance of sandwich panels relies on composite action between the core and the metal sheets. The behaviour of these panels is relatively simple to analyse using conventional principles of structural mechanics. Simple beam and plate theory, however, cannot be used. This is because the shear flexibility of the core affects the global and local (cross sectional) stress distribution, hence is required to be taken into account.

For the purpose of structural analysis, sandwich panels may be divided into two categories:

- Panels with at least one face fully profiled (typically referred to as 'fully profiled' panels)

- Panels with flat and / or lightly profiled faces.

For fully profiled sandwich panels, both the stiffness of the profiled faces and the flexibility of the core must be taken into account, creating a local static indeterminacy within the cross section even for single-span cases. This is not the case for panels with flat or lightly profiled faces, where the bending stiffness of the faces is ignored and the problem is statically determinate single span cases. For continuous fully profiled panels with two or more spans, a global static indeterminacy exists in addition to the local, making the problem of calculation of stress resultants even more complicated. Stamm \& Witte [6] have demonstrated explicit exact solutions based on governing differential equations by Allen [7]. These were used to estimate the distribution of bending moments and shear forces across the length of single span sandwich 
panels when under uniformly distributed load, point load at any location and uniform temperature load.

Davies [2] highlighted the exact analytical solutions by Stamm \& Witte [6] for single-span cases and presented a novel finite element model which yields highly accurate results. Davies [3] later extended this model to account for in-plane axial loading due to thermal bowing.

Berner [5] presented approximate analytical solutions for single-span and graphical solutions for continuous double- and three-span cases, which have limited ranges of application for continuous spans as discussed by Heywood et.al. [4]. The range of depths covered by the graphs is insufficient to provide the levels of insulation necessary to satisfy modern regulations for conservation of energy in buildings.

Davies et. al. [8] presented the exact solutions from both Stamm \& Witte [6] and Davies [2], together with the approximate analytical and graphical solutions by Berner [5] for single-, double- and multi-span arrangements. Particularly for continuous arrangements, Davies et. al. [8] recommend that if an exact solution is to be found for double- or multi- span arrangements this may be done using the fundamental equations for single-span under distributed, point or thermal load and superposing the various loading arrangements.

ECCS Recommendations [1] offered, for first time, analytical solutions for double-span continuous panel arrangements of equal spans for both uniformly distributed structural and thermal loads. The proposed equations are exact and offer designers the choice to depart from the approximate graphical solutions provided by Berner [5], which are also presented in ECCS Recommendations [1], at the cost of additional, but relatively simple, computational effort. Furthermore, the exact solutions are not limited by the dimensions of the panel and, therefore, are applicable to any geometry. The case of thermal loading is however presented with sign 
errors that yield erroneous results ${ }^{*}$. No solutions are offered for multi-span arrangements, but the designer is prompted to use the double-span case instead, an approach which yields conservative results.

EN 14509:2013 [9] is the current European Standard for manufacturing, design and testing of sandwich panels. It is an evolution of ECCS Recommendations [1] and an update to the superseded EN 14509:2006 [10]. The superseded standard presented the approximate solution for single-span cases under distributed thermal and structural load as shown by Berner [5]. EN 14509:2013 [9] substituted the approximate for the exact solution which relies on the early literature of Stamm and Witte [6]. There is an absence of guidance for continuous panel cases within the standard. Instead, designers are prompted to seek further guidance from external sources such as Davies et. al. [8].

Heywood et. al. [4] developed a set of approximate solutions for double- and multi-span span arrangements to extend the range of the graphs developed by Berner [5]. The aim was to offer guidance for fully profiled panels with modern specifications and increased core thicknesses. The guidance was derived from finite element analysis and structural testing to demonstrate the validity of the output. The main drawback of that particular guidance is that it is semiempirical and conservative.

Gosowski and Gosowski [11], [12] developed distributional solutions which take into account the flexibility of the supports. The authors demonstrated that changes in the bending moment distribution occur when the support flexibility is varied and are particularly useful for cases of arbitrary spaced supports and when the elasticity of the panel's supports is known.

\footnotetext{
${ }^{*}$ Terms $\varepsilon_{5}, \varepsilon_{7}$ and $\mathrm{M}_{\mathrm{F} 1}$ should be calculated with a sign opposite than the one presented in ECCS Recommendations (2000)
} 
All the above-mentioned methods concern the elastic stage of the panel response. The use of elastic methods is appropriate for Ultimate Limit States (ULS) and Serviceability Limit States (SLS) checks according to EN 14509:2013 [9]. For single-span arrangements, the response is elastic until the resistance of the sheets in tension or compression or the resistance of the core in shear or compression are exceeded and ultimate failure occurs (ULS). SLS conditions refer to deflection limitations only. For continuous panel arrangements, EN 14509:2013 [9] categorises failure of the supports at either bending (compression or tensions yielding of the sheets) or core crushing as SLS (together with deflection limitations at the spans). This is because the aforementioned failure modes do not lead to ultimate failure and global collapse. The response is elastic until these modes occur. Hence, the SLS term in EN 14509:2013 [9] refers to the maximum working load and prevention of any kind of failure at that magnitude is necessary. Since this SLS failure modes occur prior to failure in the spans, they usually govern the design of the panel. It is worth highlighting that EN 14509:2013 [9] uses a load factor of 1.0 for the working load (SLS).

For ultimate failure of continuous arrangements, a pseudo-plastic approach is adopted by EN 14509:2013 [9] in which it is assumed that a plastic hinge with zero moment capacity is formed at the intermediate support at the initial working load failure after which the arrangement becomes a series of single-spans. In reality, some moment redistribution may occur depending on the failure mode at or near the supports, often resulting to significant reserve of strength as observed in practice. Hassinen and Martikainen [13], [14] noted that if bending failure initially occurs at the supports of a continuous panel arrangement, then an important level of rotational capacity may be maintained. However, for shear failure, the remaining rotational capacity is practically zero. Plastic design at ULS is not a common practice for sandwich panels and there has been very little research done on this matter. 


\section{Research programme}

The following research programme was undertaken by the authors at Oxford Brookes University and was designed to:

- Produce exact analytical solutions as new design method for the analysis of continuous triple-span sandwich panels with fully profiled faces

- Experimentally examine the behaviour of continuous triple-span sandwich panels with modern specifications in bending and compare the results against the basis of the new design guidance.

The new design method was produced and validated through a combination of mathematical analysis and experimental investigation. The research was carried out in three stages:

- Development of a set of exact analytical solutions to describe the elastic behaviour of triple-span sandwich panel arrangements in bending, based on fundamental equations provided by Stamm and Witte [6]

- Testing of single- and triple- span sandwich panels in bending and examination of their structural response within the elastic stage, and observing the post-elastic stages until ultimate failure

- Evaluation of the reliability of the developed mathematical tools by comparison of theoretical performance against test results.

The presented solutions are applicable to the elastic stage of the response, which typically governs the design of continuous panel arrangements. The post-elastic panel stage was not considered in the current paper and is part of on-going research currently being undertaken by the authors. 
The research addresses the lack of exact analytical guidance for multi-span fully profiled sandwich panel arrangements by deriving and validating exact analytical solutions for triplespan arrangements of equal spans under distributed structural load and offering them in an analytical form. Triple-span solutions are considered representative of multi-span cases, since the end spans are the critical ones in terms of stiffness and developed bending moments. The developed analytical solutions presented in the current paper are directly applicable to any profiled panel specification and are easy to be used by designers with relatively little computational effort. Furthermore, since they refer back to the governing differential equations which are given in primary sources (Stamm and Witte [6]) and presented in more modern literature (Davies et. al. [8]) included as a reference to the current European Standard EN 14509:2013 [9], they have the benefit of not conflicting with the design standard itself.

\section{Mathematical basis for structural analysis}

The application of external load to a sandwich panel causes development of stresses which are assumed to be separated between two load-carrying systems, namely the 'flange' and the 'sandwich' part (Stamm and Witte [6]). The 'flange' part refers to the bending resistance and stiffness of the steel faces about their neutral axis, while the 'sandwich' part refers to the bending action about the neutral axis of the sandwich panel. The 'flange' contribution is dependant solely on the geometry and material properties of the two faces, while the 'sandwich' contribution also depends on the depth and properties of the core. The 'sandwich' part distributes the applied load as axial forces in the steel faces while concurrently resisting the developed shear force. The separation of the load-carrying systems and the distribution of stresses are illustrated in Figure 1. 
a)

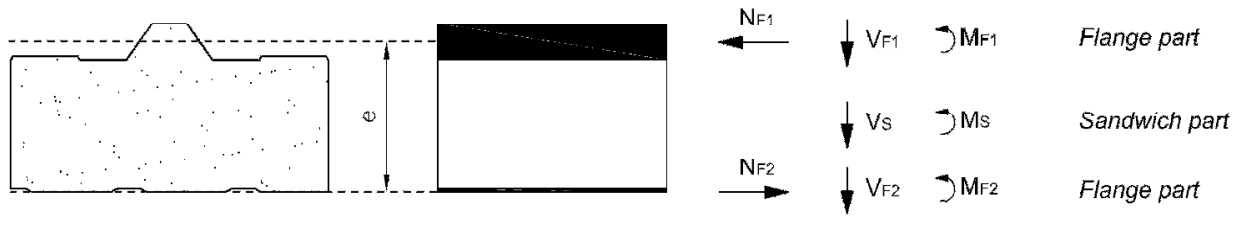

b)
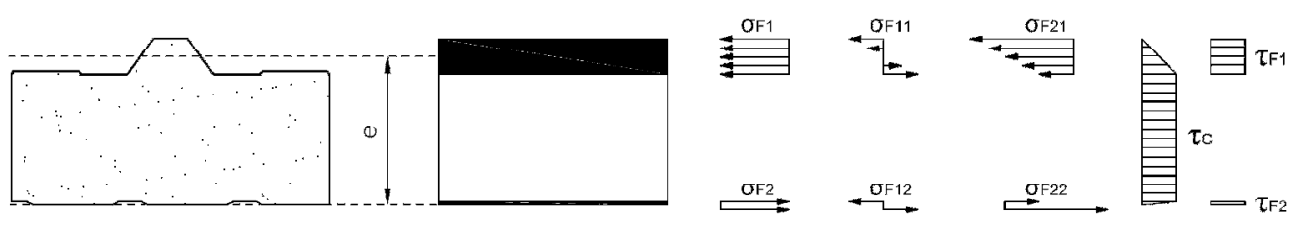

Figure 1 (a) Stress resultant and separation into 'sandwich' and 'flange' part. (b) Stress distribution over the depth of the cross-section. (Adapted from EN 14509:2013 [9])

The cross-sectional distribution of stresses between the 'flange' and the 'sandwich' part is a statically indeterminate problem. The mathematical basis of the analysis of profiled sandwich panels has previously been demonstrated by Stamm and Witte [6] and is summarised in the current section. The fundamental cases of a simply supported sandwich panel with profiled faces under uniformly distributed and point load are demonstrated. The uniform temperature load case did not form part of the current research and is omitted from this paper.

The bending stiffness of the 'sandwich' part is given by the following relationship:

$$
B_{S}=\frac{E_{F 1} A_{F 1} E_{F 2} A_{F 2} e^{2}}{E_{F 1} A_{F 1}+E_{F 2} A_{F 2}}
$$

The bending stiffness of the 'flange' part is given by the following relationship:

$$
B_{D}=E_{F 1} I_{F 1}+E_{F 2} I_{F 2}
$$

The bending stiffness of the panel is given by the following relationship:

$$
B=B_{D}+B_{S}
$$

For uniformly distributed load $q$ at any location the deflections may be calculated using the following relationship: 
$\Delta(\xi, q, L, B, \alpha, \lambda)$

$$
=\frac{q L^{4}}{B}\left(\frac{1}{24} \xi\left(1-2 \xi^{2}+\xi^{3}\right)+\frac{\xi(1-\xi)}{2 \alpha \lambda^{2}}-\frac{\cosh \left(\frac{\lambda}{2}\right)-\cosh \left(\lambda \frac{(1-2 \xi)}{2}\right)}{\alpha \lambda^{4} \cosh \left(\frac{\lambda}{2}\right)}\right)
$$

For point load $P$ at any location the deflections may be calculated by the following relationship:

$$
\begin{aligned}
& \delta(\xi, \varepsilon, P, L, B, \alpha, \lambda) \\
& =\left\{\begin{array}{l}
\frac{P L^{3}}{B}\left(\frac{1}{6}(1-\varepsilon) \xi\left(2 \varepsilon-\varepsilon^{2}-\xi^{2}\right)+\frac{(1-\varepsilon) \xi}{\alpha \lambda^{2}}-\frac{\sinh (\lambda(1-\varepsilon)) \sinh (\lambda \xi)}{\alpha \lambda^{3} \sinh (\lambda)}\right) \text { if } \xi<\varepsilon \\
\frac{P L^{3}}{B}\left(\frac{1}{6}(1-\xi) \varepsilon\left(2 \xi-\varepsilon^{2}-\xi^{2}\right)+\frac{(1-\xi) \varepsilon}{\alpha \lambda^{2}}-\frac{\sinh (\lambda \varepsilon) \sinh (\lambda(1-\xi))}{\alpha \lambda^{3} \sinh (\lambda)}\right) \text { if } \xi \geq \varepsilon
\end{array}\right.
\end{aligned}
$$

For uniformly distributed load $q$ at any location the bending moment in the 'flange' part may be calculated using the following relationship:

$$
M_{D q}(\xi, q, L, \alpha, \lambda)=q L^{2} \frac{\alpha}{1+\alpha}\left(\frac{1}{2} \xi(1-\xi)+\frac{\cosh \left(\frac{\lambda}{2}\right)-\cosh \left(\frac{\lambda}{2}(1-2 \xi)\right)}{\alpha \lambda^{2} \cosh \left(\frac{\lambda}{2}\right)}\right)
$$

For uniformly distributed load $q$ at any location the bending moment in the 'sandwich' part may be calculated using the following relationship:

$$
M_{S q}(\xi, q, L, \alpha, \lambda)=q L^{2} \frac{1}{1+\alpha}\left(\frac{1}{2} \xi(1-\xi)+\frac{\cosh \left(\frac{\lambda}{2}\right)-\cosh \left(\frac{\lambda}{2}(1-2 \xi)\right)}{\lambda^{2} \cosh \left(\frac{\lambda}{2}\right)}\right)
$$

For point load $P$ at any location the bending moment in the 'flange' part may be calculated using the following relationship:

$$
M_{D P}(\xi, \varepsilon, P, L, \alpha, \lambda)=\left\{\begin{array}{l}
-P L \frac{\alpha}{1+\alpha}\left((1-\varepsilon) \xi+\frac{\sinh (\lambda(1-\varepsilon)) \sinh (\lambda \xi)}{\alpha \lambda \sinh (\lambda)}\right) \text { if } \xi<\varepsilon \\
-P L \frac{\alpha}{1+\alpha}\left((1-\xi) \varepsilon+\frac{\sinh (\lambda \varepsilon) \sinh (\lambda(1-\xi))}{\alpha \lambda \sinh (\lambda)}\right) \text { if } \xi \geq \varepsilon
\end{array}\right.
$$

For point load $P$ at any location the bending moment in the 'sandwich' part may be calculated using the following relationship: 


$$
M_{S P}(\xi, \varepsilon, P, L, \alpha, \lambda)=\left\{\begin{array}{l}
-P L \frac{1}{1+\alpha}\left((1-\varepsilon) \xi+\frac{\sinh (\lambda(1-\varepsilon)) \sinh (\lambda \xi)}{\lambda \sinh (\lambda)}\right) \text { if } \xi<\varepsilon \\
-P L \frac{1}{1+\alpha}\left((1-\xi) \varepsilon+\frac{\sinh (\lambda \varepsilon) \sinh (\lambda(1-\xi))}{\lambda \sinh (\lambda)}\right) \text { if } \xi \geq \varepsilon
\end{array}\right.
$$

Where:

$$
\begin{aligned}
& \qquad \xi=\frac{x}{L} \text { is the location within the panel } \\
& \varepsilon=\frac{x}{L} \text { is the location of the applied load within the panel } \\
& \alpha=\frac{B_{D}}{B_{S}} \\
& \beta=\frac{B_{S}}{A_{C} G_{e f f} L^{2}} \\
& G_{e f f}=G_{C} \frac{e}{d_{C}} \\
& \lambda^{2}=\frac{1+\alpha}{\alpha \beta}
\end{aligned}
$$

and $L$ is the span of the panel.

Eq. ( 4 ) to Eq. ( 9 ) have been derived by Stamm and Witte [6] directly from the governing differential equations describing the structural behaviour of sandwich beams, hence they are exact. These are also presented in Davies et. al. [8].

The approximate graphical solutions provided by Berner [5] and Heywood et. al. [4] facilitate the estimation of the global and local stress distribution factors. The exact analytical solutions by ECCS Recommendations [1] do not directly distinguish between the two distributional parameters and are relatively easy to use based on little computational effort.

\section{Development of analytical solutions for triple-span panels}

Based on the fundamental cases described in Section 4 and particularly on Eq. ( 4 ) to Eq. ( 9 ), analytical solutions for the statically indeterminate triple-span arrangements with equal spans were developed to describe the distribution of bending moments at the support locations. The solutions were produced on the basis of superimposing the results of a single-span $3 \mathrm{~L}$ length 
panel under uniformly distributed load and point loads at the support locations. The point loads are calculated so that they cause zero net deflection when acting together with the uniformly distributed load and the point load at the adjacent support. A graphical explanation is given in Figure 2.

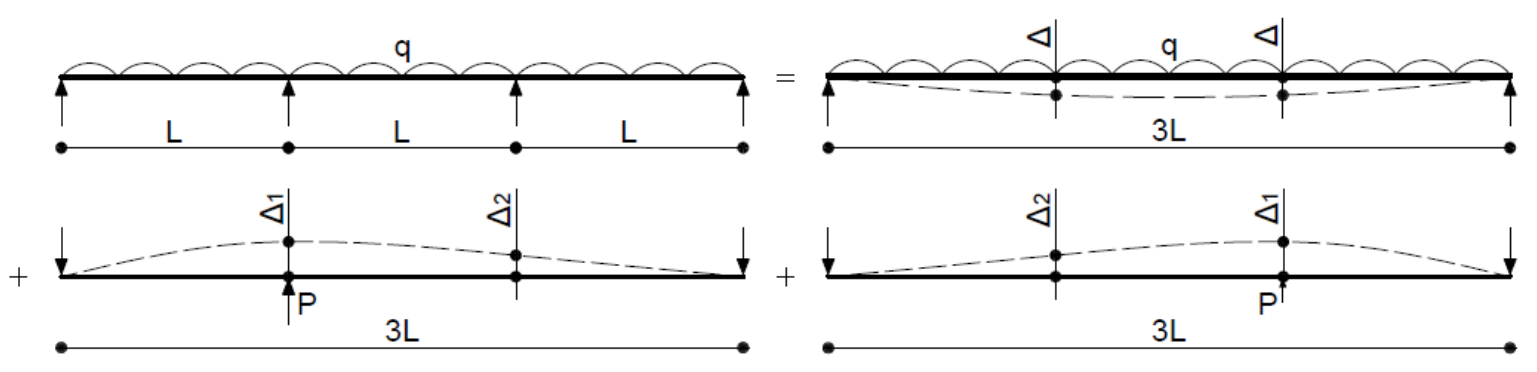

Figure 2 Basis of triple-span solution. (Adapted from Davies [2])

Based on Eq. ( 4 ) the deflections at the support locations under uniformly distributed load are given by:

$$
\Delta\left(\frac{1}{3}, q, L, B, \alpha, \lambda\right)=\Delta\left(\frac{2}{3}, q, L, B, \alpha, \lambda\right)=\frac{q L^{4}}{B}\left(\frac{1}{9 \alpha \lambda^{2}}-\frac{\cosh \left(\frac{\lambda}{2}\right)-\cosh \left(\frac{\lambda}{6}\right)}{\alpha \lambda^{4} \cosh \left(\frac{\lambda}{2}\right)}+\frac{11}{972}\right)
$$

Based on Eq. ( 5 ) the deflections at the support locations under unity point loads at the supports are given by:

$$
\left\{\begin{array}{c}
\delta\left(\frac{1}{3}, \frac{1}{3}, P, L, B, \alpha, \lambda\right)=\delta\left(\frac{2}{3}, \frac{2}{3}, P, L, B, \alpha, \lambda\right)=\frac{L^{3}}{B}\left(\frac{2}{9 \alpha \lambda^{2}}-\frac{\sinh \left(\frac{\lambda}{3}\right) \sinh \left(\frac{2 \lambda}{3}\right)}{\alpha \lambda^{3} \sinh (\lambda)}+\frac{4}{243}\right) \\
\delta\left(\frac{1}{3}, \frac{2}{3}, P, L, B, \alpha, \lambda\right)=\delta\left(\frac{2}{3}, \frac{1}{3}, P, L, B, \alpha, \lambda\right)=\frac{L^{3}}{B}\left(\frac{2}{9 \alpha \lambda^{2}}-\frac{\left(\sinh \left(\frac{\lambda}{3}\right)\right)^{2}}{\alpha \lambda^{3} \sinh (\lambda)}+\frac{7}{486}\right)
\end{array}\right\}
$$

Solving for deflection compatibility:

$$
\left\{\begin{array}{l}
P\left(\frac{1}{3}\right) \cdot \delta\left(\frac{1}{3}, \frac{1}{3}, P, L, B, \alpha, \lambda\right)+P\left(\frac{2}{3}\right) \cdot \delta\left(\frac{1}{3}, \frac{2}{3}, P, L, B, \alpha, \lambda\right)=\Delta\left(\frac{1}{3}, q, L, B, \alpha, \lambda\right) \\
P\left(\frac{2}{3}\right) \cdot \delta\left(\frac{2}{3}, \frac{1}{3}, P, L, B, \alpha, \lambda\right)+P\left(\frac{2}{3}\right) \cdot \delta\left(\frac{2}{3}, \frac{2}{3}, P, L, B, \alpha, \lambda\right)=\Delta\left(\frac{2}{3}, q, L, B, \alpha, \lambda\right)
\end{array}\right\}
$$

For $P(1 / 3)=P(2 / 3)=P$, the solution for the point load $P$ becomes: 


$$
\begin{aligned}
P(q, L, B, \alpha, \lambda) & =\frac{\Delta\left(\frac{1}{3}, q, L, B, \alpha, \lambda\right)}{\delta\left(\frac{1}{3}, \frac{1}{3}, P, L, B, \alpha, \lambda\right)+\delta\left(\frac{1}{3}, \frac{2}{3}, P, L, B, \alpha, \lambda\right)} \\
& =\frac{\Delta\left(\frac{2}{3}, q, L, B, \alpha, \lambda\right)}{\delta\left(\frac{2}{3}, \frac{1}{3}, P, L, B, \alpha, \lambda\right)+\delta\left(\frac{2}{3}, \frac{2}{3}, P, L, B, \alpha, \lambda\right)}
\end{aligned}
$$

A dimensionless value for the point load equation is required. Hence, with some rearrangement, set:

$$
\varepsilon_{1}(\alpha, \lambda)=\frac{P(q, L, B, \alpha, \lambda)}{q L}=\frac{\frac{1}{9 \alpha \lambda^{2}}-\frac{\cosh \left(\frac{\lambda}{2}\right)-\cosh \left(\frac{\lambda}{6}\right)}{\alpha \lambda^{4} \cosh \left(\frac{\lambda}{2}\right)}+\frac{11}{972}}{\frac{1}{3 \alpha \lambda^{2}}-\frac{\left(\sinh \left(\frac{\lambda}{3}\right)\right)^{2}}{\alpha \lambda^{3} \sinh (\lambda)}-\frac{\sinh \left(\frac{\lambda}{3}\right) \sinh \left(\frac{2 \lambda}{3}\right)}{\alpha \lambda^{3} \sinh (\lambda)}+\frac{5}{162}}
$$

Based on Eq. ( 6 ) and Eq. ( 7 ) the bending moments in the "flange" and "sandwich" parts due to uniformly distributed load $q$ become:

$$
\begin{aligned}
& M_{D q}\left(\frac{1}{3}, q, L, \alpha, \lambda\right)=M_{D q}\left(\frac{2}{3}, q, L, \alpha, \lambda\right)=q L^{2} \frac{\alpha}{1+\alpha}\left(\frac{\cosh \left(\frac{\lambda}{2}\right)-\cosh \left(\frac{\lambda}{6}\right)}{\alpha \lambda^{2} \cosh \left(\frac{\lambda}{2}\right)}+\frac{1}{9}\right) \\
& M_{S q}\left(\frac{1}{3}, q, L, \alpha, \lambda\right)=M_{S q}\left(\frac{1}{3}, q, L, \alpha, \lambda\right)=q L^{2} \frac{1}{1+\alpha}\left(\frac{\cosh \left(\frac{\lambda}{2}\right)-\cosh \left(\frac{\lambda}{6}\right)}{\lambda^{2} \cosh \left(\frac{\lambda}{2}\right)}-\frac{1}{9}\right)
\end{aligned}
$$

With some rearrangement, set:

$$
\begin{aligned}
& \varepsilon_{2}(\alpha, \lambda)=\frac{M_{D q}\left(\frac{1}{3}, q, L, \alpha, \lambda\right)}{q L^{2}}=\frac{M_{D q}\left(\frac{2}{3}, q, L, \alpha, \lambda\right)}{q L^{2}}=\frac{\alpha}{1+\alpha}\left(\frac{\cosh \left(\frac{\lambda}{2}\right)-\cosh \left(\frac{\lambda}{6}\right)}{\alpha \lambda^{2} \cosh \left(\frac{\lambda}{2}\right)}+\frac{1}{9}\right) \\
& \varepsilon_{3}(\alpha, \lambda)=\frac{M_{S q}\left(\frac{1}{3}, q, L, \alpha, \lambda\right)}{q L^{2}}=\frac{M_{S q}\left(\frac{2}{3}, q, L, \alpha, \lambda\right)}{q L^{2}}=\frac{1}{1+\alpha}\left(\frac{\cosh \left(\frac{\lambda}{2}\right)-\cosh \left(\frac{\lambda}{6}\right)}{\lambda^{2} \cosh \left(\frac{\lambda}{2}\right)}-\frac{1}{9}\right)
\end{aligned}
$$

Based on Eq. ( 8 ) and Eq. ( 9 ) the bending moments in the "flange" and "sandwich" parts due to point load $P$ become: 


$$
\begin{gathered}
\left\{\begin{array}{c}
M_{D P}\left(\frac{1}{3}, \frac{1}{3}, P, L, \alpha, \lambda\right)=M_{D P}\left(\frac{1}{3}, \frac{2}{3}, P, L, \alpha, \lambda\right)=P L \frac{\alpha}{1+\alpha}\left(\frac{\sinh \left(\frac{\lambda}{3}\right) \sinh \left(\frac{2 \lambda}{3}\right)}{\alpha \lambda \sinh (\lambda)}+\frac{2}{9}\right) \\
M_{D P}\left(\frac{2}{3}, \frac{1}{3}, P, L, \alpha, \lambda\right)=M_{D P}\left(\frac{2}{3}, \frac{2}{3}, P, L, \alpha, \lambda\right)=P L \frac{\alpha}{1+\alpha}\left(\frac{\left(\sinh \left(\frac{\lambda}{3}\right)\right)^{2}}{\alpha \lambda \sinh (\lambda)}+\frac{1}{9}\right)
\end{array}\right\} \\
\left\{\begin{array}{c}
M_{S P}\left(\frac{1}{3}, \frac{1}{3}, P, L, \alpha, \lambda\right)=M_{D P}\left(\frac{1}{3}, \frac{2}{3}, P, L, \alpha, \lambda\right)=P L \frac{\alpha}{1+\alpha}\left(\frac{\sinh \left(\frac{\lambda}{3}\right) \sinh \left(\frac{2 \lambda}{3}\right)}{\lambda \sinh (\lambda)}-\frac{2}{9}\right) \\
M_{S P}\left(\frac{2}{3}, \frac{1}{3}, P, L, \alpha, \lambda\right)=M_{D P}\left(\frac{2}{3}, \frac{2}{3}, P, L, \alpha, \lambda\right)=P L \frac{\alpha}{1+\alpha}\left(\frac{\left(\sinh \left(\frac{\lambda}{3}\right)\right)^{2}}{\lambda \sinh (\lambda)}-\frac{1}{9}\right)
\end{array}\right\}
\end{gathered}
$$

With some rearrangement, set:

$$
\begin{gathered}
\varepsilon_{4}(\alpha, \lambda)=\varepsilon_{1}(\alpha, \lambda) \cdot \frac{M_{D P}\left(\frac{1}{3}, \frac{1}{3}, P, L, \alpha, \lambda\right)+M_{D P}\left(\frac{2}{3}, \frac{1}{3}, P, L, \alpha, \lambda\right)}{P L} \\
=\varepsilon_{1}(\alpha, \lambda) \cdot \frac{M_{D P}\left(\frac{1}{3}, \frac{2}{3}, P, L, \alpha, \lambda\right)+M_{D P}\left(\frac{2}{3}, \frac{2}{3}, P, L, \alpha, \lambda\right)}{P L} \\
=-\varepsilon_{1}(\alpha, \lambda) \cdot \frac{\alpha}{1+\alpha}\left(\frac{\sinh \left(\frac{\lambda}{3}\right) \sinh \left(\frac{2 \lambda}{3}\right)+\left(\sinh \left(\frac{\lambda}{3}\right)\right)^{2}}{\alpha \lambda \sinh (\lambda)}+\frac{3}{9}\right) \\
\begin{aligned}
\varepsilon_{5}(\alpha, \lambda)=\varepsilon_{1}(\alpha, \lambda) \cdot \frac{M_{S P}\left(\frac{1}{3}, \frac{1}{3}, P, L, \alpha, \lambda\right)+M_{S P}\left(\frac{2}{3}, \frac{1}{3}, P, L, \alpha, \lambda\right)}{P L} \\
=\varepsilon_{1}(\alpha, \lambda) \cdot \frac{M_{S P}\left(\frac{1}{3}, \frac{2}{3}, P, L, \alpha, \lambda\right)+M_{S P}\left(\frac{2}{3}, \frac{2}{3}, P, L, \alpha, \lambda\right)}{P L} \\
=\varepsilon_{1}(\alpha, \lambda) \cdot \frac{\alpha}{1+\alpha}\left(\frac{\sinh \left(\frac{\lambda}{3}\right) \sinh \left(\frac{2 \lambda}{3}\right)+\left(\sinh \left(\frac{\lambda}{3}\right)\right)^{2}}{\lambda \sinh (\lambda)}-\frac{3}{9}\right)
\end{aligned}
\end{gathered}
$$

The bending moments in the 'flange' and 'sandwich' part at the support for combined uniform distributed load and point loads are given by:

$$
\begin{aligned}
& M_{D}(\xi, \varepsilon, P, L, \alpha, \lambda)=M_{D q}(\xi, q, L, \alpha, \lambda)+M_{D P}\left(\xi, \frac{1}{3}, P, L, \alpha, \lambda\right)+M_{D P}\left(\xi, \frac{2}{3}, P, L, \alpha, \lambda\right) \\
& M_{S}(\xi, \varepsilon, P, L, \alpha, \lambda)=M_{S q}(\xi, q, L, \alpha, \lambda)+M_{S P}\left(\xi, \frac{1}{3}, P, L, \alpha, \lambda\right)+M_{S P}\left(\xi, \frac{2}{3}, P, L, \alpha, \lambda\right)
\end{aligned}
$$

The total bending moment over the support is: 


$$
M_{\text {sup }}=-\frac{q\left(\frac{L}{3}\right)^{2}}{8}=-\frac{q L^{2}}{72}
$$

The bending moment in the 'flange' and 'sandwich' parts at the supports may be calculated using the following relationships:

$$
\begin{aligned}
& M_{D}=\varepsilon_{6}(\alpha, \lambda) \cdot M_{\text {sup }} \\
& M_{S}=\varepsilon_{7}(\alpha, \lambda) \cdot M_{\text {sup }}
\end{aligned}
$$

Where, $\varepsilon_{6}$ and $\varepsilon_{7}$ describe the proportion of the bending moment that is distributed between the 'flange' and 'sandwich' components respectively at the supports, by setting:

$$
\begin{aligned}
& \varepsilon_{6}(\alpha, \lambda)=-72\left(\varepsilon_{2}(\alpha, \lambda)+\varepsilon_{4}(\alpha, \lambda)\right) \text { ('flange') } \\
& \varepsilon_{7}(\alpha, \lambda)=-72\left(\varepsilon_{3}(\alpha, \lambda)+\varepsilon_{5}(\alpha, \lambda)\right) \text { ('sandwich') }
\end{aligned}
$$

The distribution of bending moment at the supports for triple-span arrangements with equal spans under distributed load may be calculated by simply determining the factors $\varepsilon_{1}, \varepsilon_{2}, \varepsilon_{3}, \varepsilon_{4}$, $\varepsilon_{5}, \varepsilon_{6}$ and $\varepsilon_{7}$ which rely on parameters $\alpha$ and $\lambda$. This format is fairly consistent with that presented in ECCS Recommendations [1] for double-span arrangements.

The developed analytical solutions refer back to the governing differential equations for sandwich beams by Stamm and Witte [6], hence they are exact.

\section{Experimental investigation and validation}

\subsection{Test programme}

The test programme was devised to examine the structural response of single- and triple- span panels under structural load and to validate the basis of the design method. A series of bending tests were conducted on steel-faced sandwich panels with one face fully profiled and one face lightly profiled, $80 \mathrm{~mm}$ deep PIR cores and $31.3 \mathrm{~mm}$ deep profiles. Tests comprised single- and 
triple- span arrangements. The cross-section of the panels and their nominal dimensions was as shown in Figure 3.

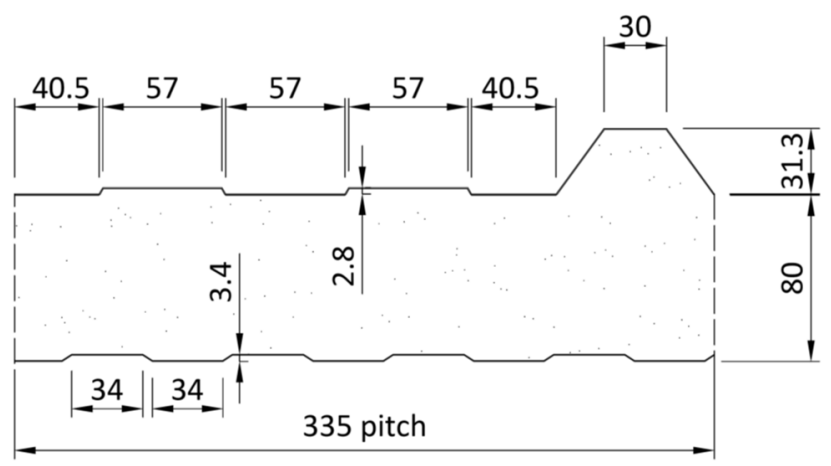

Figure 3 Cross-section of tested sandwich panels (dimensions in $\mathbf{m m}$ )

The single-span group of tests examined the behaviour of panels in the elastic stage and their performance in terms of stiffness. The triple- span group of tests examined the behaviour of panels in terms of stiffness and initial failure, and allowed observation of post-elastic behaviour and strength prior to global failure. All the tests were used to generate data to compare against the results of existing exact solution methods.

Table 1 schedules the range of tests that were carried out. Span lengths were chosen to ensure bending failure for the given core depth.

Table 1 Test series on profiled sandwich panels

\begin{tabular}{|l|l|c|c|c|}
\hline Test reference & Panel No. & Core depth $\mathbf{( m m )}$ & Arrangement & Clear span (m) \\
\hline S-1-01 & 1 & & \multirow{2}{*}{ Single-span } & 6.00 \\
\hline S-1-02 & 2 & & & \\
\cline { 1 - 2 } S-1-03 & 3 & 80 & Triple-span & 2.00 \\
\hline S-3-03 & 3 & & & \\
\hline S-3-02 & 2 & & & \\
\hline S-3-01 & 1 & & & \\
\hline
\end{tabular}

The material properties of the steel faces and the PIR core were provided by the manufacturer. The mechanical properties were derived from samples taken from panels from the same production run as that of the test specimens and determined according to the test procedures of 
EN 14509:2013 [9]. The measured and nominal material properties are shown in Table 2 and

Table 3. These data were used throughout the theoretical analysis of the tests.

Table 2 Material properties and dimensions for steel faces

\begin{tabular}{|l|l|l|l|l|}
\hline \multicolumn{1}{|c|}{ Face } & \multicolumn{1}{|c|}{$\begin{array}{c}\text { Thickness } \\
\mathbf{t}_{\mathbf{F}}(\mathbf{m m})\end{array}$} & $\begin{array}{c}\text { Yield strength } \\
\mathbf{f}_{\mathbf{y}}(\mathbf{M P a})\end{array}$ & $\begin{array}{c}\text { Ultimate strength } \\
\mathbf{f}_{\mathbf{u}}(\mathbf{M P a})\end{array}$ & $\begin{array}{c}\text { Young's modulus } \\
\mathbf{E}_{\mathbf{F}}(\mathbf{M P a})\end{array}$ \\
\cline { 2 - 5 } & \multicolumn{3}{|c|}{ Measured } & Nominal \\
\hline Profiled (external) & 0.442 & 357 & 416 & 210,000 \\
\hline Lightly profiled (liner) & 0.302 & 372 & 436 & 210,000 \\
\hline
\end{tabular}

Table 3 Material properties for the PIR insulation core

\begin{tabular}{|c|c|c|c|c|c|c|c|c|}
\hline \multirow{3}{*}{$\begin{array}{l}\text { Density } \\
\left(\mathrm{kg} / \mathrm{m}^{3}\right)\end{array}$} & \multicolumn{6}{|c|}{ Modulus } & \multicolumn{2}{|c|}{ Strength } \\
\hline & \multicolumn{2}{|c|}{$\begin{array}{c}\text { Shear } \\
\text { Gc (MPa) }\end{array}$} & \multicolumn{2}{|c|}{$\begin{array}{c}\text { Compression } \\
\text { E }_{\mathrm{cc}}(\mathbf{M P a})\end{array}$} & \multicolumn{2}{|c|}{$\begin{array}{c}\text { Tension } \\
\text { Ect }_{\text {ct }}(\mathrm{MPa})\end{array}$} & $\begin{array}{l}\text { Shear } \mathbf{f}_{\mathrm{cv}} \\
\text { (MPa) }\end{array}$ & $\begin{array}{c}\text { Compression } \\
\text { f }_{\mathrm{cc}}(\mathrm{MPa})\end{array}$ \\
\hline & Measured & Mean & Measured & Mean & Measured & Mean & & ominal \\
\hline 40.05 & $\begin{array}{l}2.62 \\
2.40\end{array}$ & 2.51 & $\begin{array}{l}1.980 \\
1.986 \\
2.217\end{array}$ & 2.061 & $\begin{array}{l}1.155 \\
1.175 \\
1.219\end{array}$ & 1.183 & 0.100 & 0.114 \\
\hline
\end{tabular}

Single-span tests were based on the procedures of EN 14509:2013 [9]. A similar procedure was applied to the continuous triple-span arrangements. For the single-span arrangements, four line loads were applied across each span to simulate uniformly distributed load conditions. Due to test apparatus limitations, it was not possible to apply the load arrangement over three spans. As a result, an alternative arrangement with two line loads per span at distances of one-quarter span from the supports was applied to the triple-span case. A schematic of the loading arrangements is shown in Figure 4. All tests were carried out with the fully profiled faces uppermost to simulate a downwards (gravity) load. The bending stiffness of the panels is independent to the orientation of the faces, however the failure modes and resistance are associated with the direction of loading due to the strength variations of the faces. Figure 5 describes the test set-up for the triple- span arrangement. 

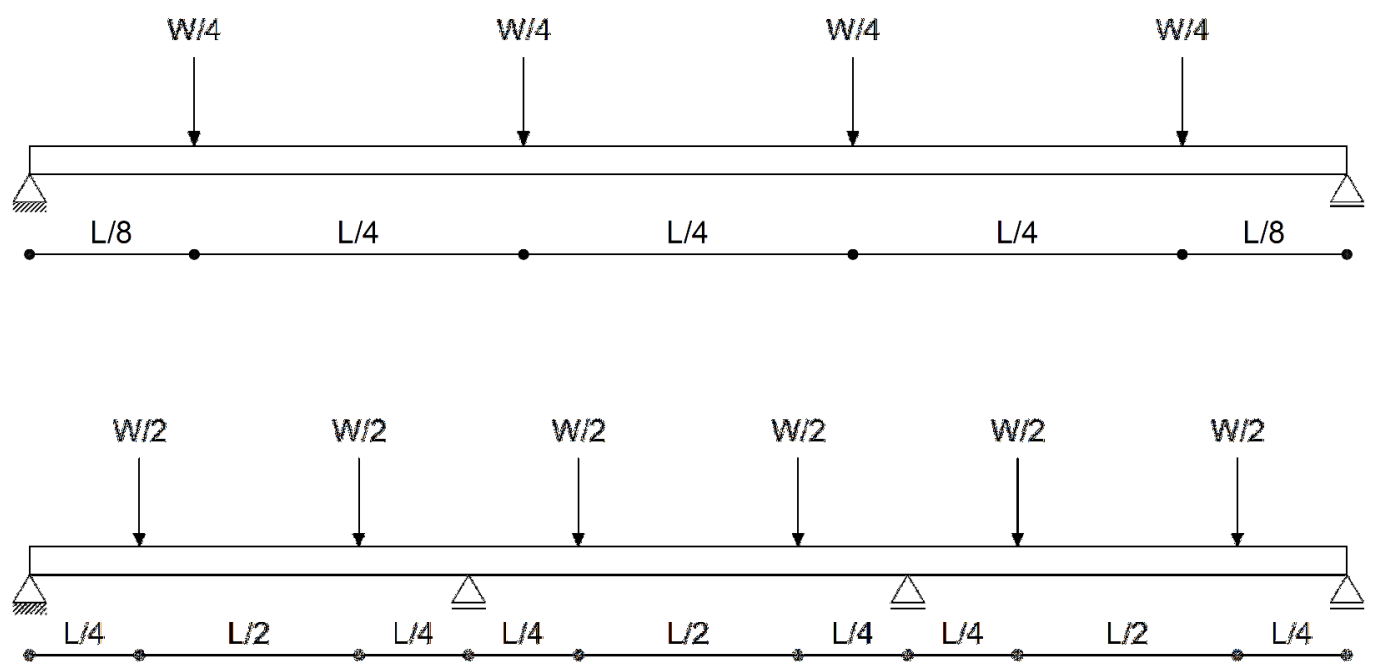

Where: $L$ is the length of the span

$W$ is the applied load in one span

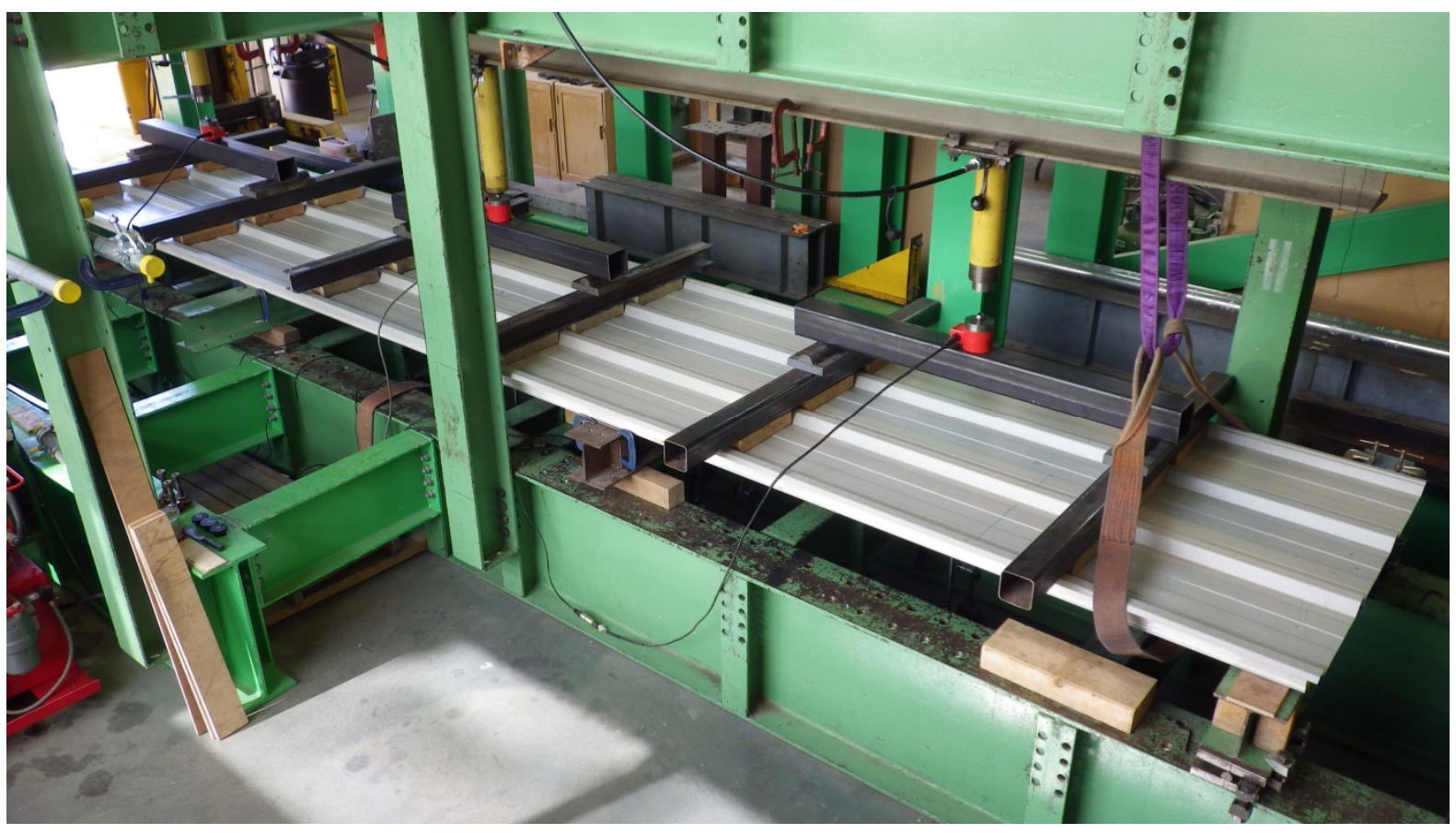

Figure 5 Triple-span test arrangement

The deflection due to self-weight were not measured. The deflection measurements were set to zero for the case of the panel resting on the supports without any externally applied load. The 
applied load was logged, together with deflection measurements at several locations, and the maximum load at global failure recorded. The failure propagation was inspected continuously throughout each test.

Load was applied by a hydraulic jack at each span and distributed through square hollow section (SHS) spreader beams. Transverse steel spreader beams were positioned beneath the longitudinal spreader beams to ensure that the load was applied to the full width of the panel. Timber loading blocks were positioned in the troughs of the profiled faces in order to avoid local damage. Rollers of $15 \mathrm{~mm}$ radius were positioned between the longitudinal and transverse spreaders. The panels were supported on steel beams with a support width of $100 \mathrm{~mm}$ at the ends and $150 \mathrm{~mm}$ at the intermediate locations to avoid premature core crushing. The support conditions applied no rotational restraint to the panel about each line of supports.

The tests were displacement controlled at a steady rate of $0.25 \mathrm{~mm} / \mathrm{sec}$. The applied load was measured by calibrated load cells positioned below the jacks. Displacements were recorded by transducers at the following locations:

- Over one of the loading jacks for deflection control

- Under the panel supports

- Under the mid-span of the panel

- Under the panel at various locations close to the supports for the triple- spans.

The load application for the continuous arrangements caused:

- compressive forces in the outer sheet and tensile forces in the liner sheet in the spans

- compressive forces in the liner sheet and tensile forces in the outer sheet at the supports (only for the continuous arrangements)

- $\quad$ support reaction forces, compressing the core at the support locations 
- shear forces across the panel length with maximum magnitudes close to the supports (the mid-support for the continuous arrangements).

\subsection{Test results and analysis for single-span arrangements}

The results for the single-span tests are shown in Table 4. The intention of the tests was solely to determine the bending stiffness of the panel arrangement and observe if any significant variation existed amongst the panels. The applied load was such that it kept each panel within the elastic stage of response, i.e. failure was intentionally not reached. The specimens were intended to be re-used later for triple- span tests.

Theoretical results in terms of experimental deflections are shown in Table 4 . These are based on the fundamental exact solutions for an identical panel arrangement. Theoretical and experimental results in terms of stiffness for each test are shown in

Table 5. The stiffness is defined per below:

$$
\text { Stiffness }=\frac{\text { Applied elastic load on panel }}{\text { Mid }- \text { span deflection for applied elastic load }}
$$

The experimental stiffness was derived from the linear trend line of the jack load and mid-span deflection. Some small discrepancies with the total load and deflection shown in Table 4 are due to load recording noise and establishment of perfect support conditions once some preload was applied. The test results were very consistent and showed excellent agreement with the developed theory in terms of bending stiffness. A mean ratio (theory / test) of 0.95 was demonstrated. 
Table 4 Single-span test results (load, deflections) and theoretical deflections

\begin{tabular}{|c|c|c|c|c|c|}
\hline \multirow[t]{2}{*}{ Test reference } & \multirow[t]{2}{*}{ Panel No. } & \multirow[t]{2}{*}{ Clear span (m) } & \multirow{2}{*}{$\begin{array}{l}\text { Max applied } \\
\operatorname{load}^{*}(\mathbf{k N})- \\
\text { elastic range }\end{array}$} & \multicolumn{2}{|c|}{ Deflection $^{* *}(\mathrm{~mm})$} \\
\hline & & & & Test & Theory $^{* * *}$ \\
\hline S-1-01 & 1 & \multirow{3}{*}{6.00} & 7.26 & 69.60 & 79.95 \\
\hline S-1-02 & 2 & & 7.11 & 71.03 & 78.15 \\
\hline S-1-03 & 3 & & 7.09 & 71.60 & 77.89 \\
\hline
\end{tabular}

${ }^{*}$ Including panel self-weight (calculated as $0.108 \mathrm{kN} / \mathrm{m}$ based on measured geometrical properties, nominal steel density and measured core density)

${ }^{* *}$ Excluding deflections due to panel self-weight

*** Based on fundamental exact solutions in Stamm and Witte [6].

Table 5 Single-span stiffness comparison between theory and test results

\begin{tabular}{|c|c|c|c|c|c|}
\hline \multirow[t]{2}{*}{ Test reference } & \multirow[t]{2}{*}{ Panel No. } & \multirow[t]{2}{*}{ Clear span (m) } & \multicolumn{2}{|c|}{ Stiffness $(\mathrm{kN} / \mathrm{mm})^{*}$} & \multirow{2}{*}{$\begin{array}{l}\text { Ratio (theory / } \\
\text { test) }\end{array}$} \\
\hline & & & Test & Theory $^{* *}$ & \\
\hline S-1-01 & 1 & \multirow{3}{*}{6.00} & 0.091 & \multirow{3}{*}{0.084} & 0.92 \\
\hline S-1-02 & 2 & & 0.087 & & 0.97 \\
\hline S-1-03 & 3 & & 0.087 & & 0.97 \\
\hline \multicolumn{5}{|c|}{ Mean } & 0.95 \\
\hline
\end{tabular}

${ }^{*}$ Excluding deflections due to panel self-weight

${ }^{* *}$ Based on fundamental exact solutions in Stamm and Witte [6].

\subsection{Test results and analysis for triple-span arrangements}

Results for the triple-span tests are shown in Table 6. The initial failure occurred as a consequence of tensile yielding of the outer sheet at one of the internal supports with a second failure resulting from yielding shortly afterwards. At the point of the second failure, a change in the bending stiffness of the panel was observed. Although this did not lead to ultimate collapse, it corresponded to the maximum working load allowed in design according to EN 14509:2013 [9]. No local buckling or wrinkling of the liner sheet over the supports was noticed. Theoretical results in terms of experimental deflections are also shown in Table 6. These are based on the fundamental exact solutions for an identical panel arrangement.

As load increased, higher compressive forces were developed in the outer sheet at the end spans, causing local buckling at the crest of the profiles, but without failure of the entire crosssection. High reaction forces caused some level of core crushing at both the end and the intermediate support locations. The post-failure inspection showed no local buckling or 
wrinkling of the liner sheet over the supports. The interaction of the different failure modes was observed as a gradual and ductile loss of stiffness. A significant reserve of strength was observed beyond the initial tensile yielding failure of the outer sheet at the support, owing to the panel arrangement's initial redundancy. Each specimen ultimately resisted almost twice the initial failure load at the end of the elastic stage.

Global failure occurred when shear stresses exceeded the shear strength of the core at the midspan support locations and consequent global instability occurred. At that point, the diminished rotational capacity of the panel at the support and the shear failure created a mechanism that led to global collapse.

Table 6 Triple-span test results (load, deflections) and theoretical deflections

\begin{tabular}{|c|c|c|c|c|c|c|c|c|c|}
\hline \multirow{3}{*}{$\begin{array}{l}\text { Test } \\
\text { reference }\end{array}$} & \multirow{3}{*}{$\begin{array}{l}\text { Panel } \\
\text { No. }\end{array}$} & \multirow{3}{*}{$\begin{array}{l}\text { Clear } \\
\text { span } \\
(\mathbf{m})\end{array}$} & \multirow{3}{*}{$\begin{array}{l}\text { Total } \\
\text { load }^{*} \\
\text { (elastic) } \\
(\mathbf{k N})\end{array}$} & \multicolumn{4}{|c|}{ Deflection $^{* *}$ (elastic) (mm) } & \multirow{3}{*}{$\begin{array}{l}\text { Total load* } \\
\text { (ultimate) } \\
(\mathbf{k N})\end{array}$} & \multirow{3}{*}{$\begin{array}{l}\text { Deflection }{ }^{* *} \\
\text { (ultimate) } \\
\text { (mm) }\end{array}$} \\
\hline & & & & \multicolumn{2}{|l|}{ Test } & \multicolumn{2}{|c|}{ Theory $^{* * *}$} & & \\
\hline & & & & $\begin{array}{l}\text { End } \\
\text { span }\end{array}$ & $\begin{array}{l}\text { Middle } \\
\text { span }\end{array}$ & $\begin{array}{l}\text { End } \\
\text { span }\end{array}$ & $\begin{array}{l}\text { Middle } \\
\text { span }\end{array}$ & & \\
\hline S-3-03 & 3 & \multirow{3}{*}{2.00} & 27.63 & 7.34 & 6.83 & 8.48 & 5.26 & 56.87 & $\begin{array}{l}18.48 \\
16.64 \\
21.37 \\
\end{array}$ \\
\hline S-3-02 & 2 & & 26.67 & 7.39 & 7.01 & 8.17 & 5.08 & 58.06 & $\begin{array}{l}18.32 \\
16.19 \\
21.35\end{array}$ \\
\hline S-3-01 & 1 & & 28.02 & 6.81 & 6.00 & 8.60 & 5.34 & 55.64 & $\begin{array}{l}16.31 \\
14.06 \\
19.00\end{array}$ \\
\hline
\end{tabular}

*Including panel self-weight

** Excluding deflections due to panel self-weight

*** Based on fundamental exact solutions in Stamm and Witte [6].

Figure 6 shows a typical load plotted against the mid-span deflection, illustrating the changes of stiffness from start until ultimate collapse. Performance divides into two discreet phases:

- Phase 1: A linear elastic response with the panel behaving similarly to a triple-span condition until initial failure due to tensile yielding of the outer sheet at the support

- Phase 2: Gradual and ductile stiffness reduction due to the initial failure and other propagating failure modes (local buckling of the profile's crests in the span and 
crushing of the core at the supports) until global failure (shear at the supports). During this stage the panel remains continuous but with a reduced rotational capacity at the support.

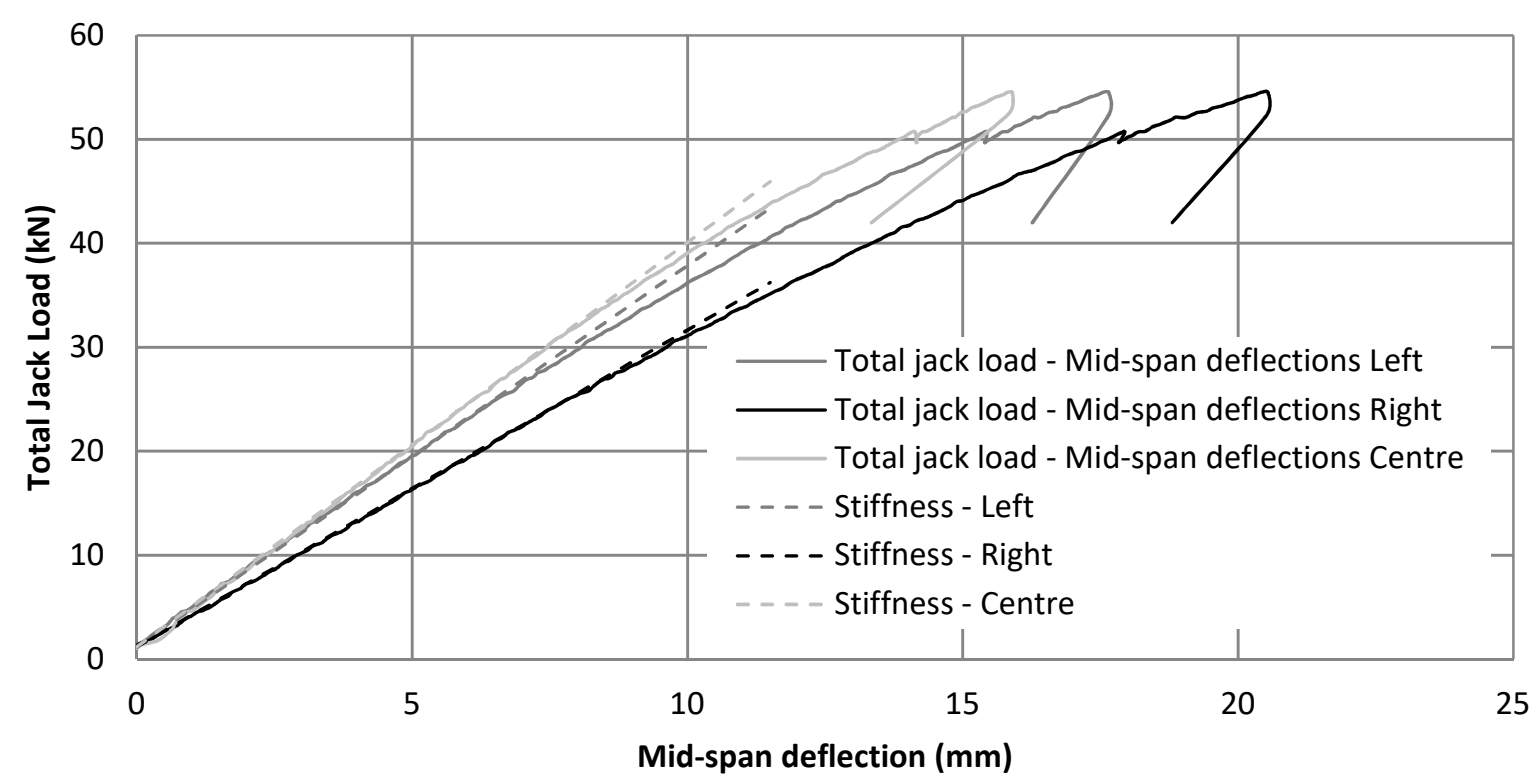

Figure 6 Typical total jack load plotted against mid-span deflection graph for 3-span panel arrangement

In order to verify the reliability of the design method presented in Section 5, the fundamental design equations, which form the basis of the new guidance, presented in Section 4 were utilised to calculate the stiffness magnitudes and the load corresponding to initial failure at the intermediate supports. These two terms are critical for working load (SLS) checks in design and are also representative of the local and global stress distribution across the panel arrangement. The experimental stiffness for each test are shown in Table 7 . These were derived from the linear trend line of the jack load and mid-span deflection data for the elastic stage of the response. Some small discrepancies with the total load and deflection shown in Table 6 are due to small variations between the three jack load recordings, load recording noise and establishment of perfect support conditions once some pre-load was applied.

The test results and theoretical predictions are shown in Table 7 and Table 8 for resistance and stiffness respectively. The theoretical results demonstrate good agreement with the tests in 
terms of the bending stiffness at the end span, but a considerable overestimation in the central span. A mean ratio (theory / test) of 0.88 and 1.22 was demonstrated for the end and central spans respectively. In terms of predicting the level of stresses and, consequently, the maximum elastic load, the theoretical model is safe and bears a high level of agreement with the test results, with a mean theory / test ratio of 0.97 .

Table 7 Triple-span maximum elastic load comparison between theory and test results

\begin{tabular}{|c|c|c|c|c|c|c|c|c|}
\hline \multirow[t]{2}{*}{$\begin{array}{l}\text { Test } \\
\text { ref. }\end{array}$} & \multirow[t]{2}{*}{$\begin{array}{l}\text { Panel } \\
\text { No. }\end{array}$} & \multirow[t]{2}{*}{$\begin{array}{l}\text { Clear } \\
\text { span }(\mathrm{m})\end{array}$} & \multicolumn{2}{|c|}{$\begin{array}{l}\text { Max elastic load } \\
(\mathrm{kN})\end{array}$} & \multicolumn{2}{|c|}{$\begin{array}{l}\text { Bending } \\
\text { moment }(\mathrm{kNm})\end{array}$} & \multirow{2}{*}{$\begin{array}{l}\text { Load ratio } \\
\text { (theory / } \\
\text { test) }\end{array}$} & \multirow[t]{2}{*}{$\begin{array}{l}\text { Bending moment } \\
\text { ratio (theory / test) }\end{array}$} \\
\hline & & & Test & Theory & Test & Theory & & \\
\hline S-3-03 & 3 & \multirow{3}{*}{2.00} & 27.63 & \multirow{3}{*}{26.53} & -0.67 & \multirow{3}{*}{-0.64} & 0.96 & 0.95 \\
\hline S-3-02 & 2 & & 26.67 & & -0.64 & & 0.99 & 1.00 \\
\hline S-3-01 & 1 & & 28.02 & & -0.68 & & 0.95 & 0.94 \\
\hline \multicolumn{7}{|c|}{ Mean } & 0.97 & 0.96 \\
\hline
\end{tabular}

*Including panel self-weight

Table 8 Triple-span stiffness comparison between theory and test results

\begin{tabular}{|c|c|c|c|c|c|c|c|c|}
\hline \multirow[t]{3}{*}{ Test reference } & \multirow[t]{3}{*}{ Panel No. } & \multirow{3}{*}{$\begin{array}{l}\text { Clear span } \\
\text { (m) }\end{array}$} & \multicolumn{4}{|c|}{ Stiffness $(\mathrm{kN} / \mathrm{mm})^{*}$} & \multirow{2}{*}{\multicolumn{2}{|c|}{$\begin{array}{l}\text { Stiffness ratio } \\
\text { (theory / test) }\end{array}$}} \\
\hline & & & \multicolumn{2}{|l|}{ Test } & \multicolumn{2}{|c|}{ Theory $^{* *}$} & & \\
\hline & & & $\begin{array}{l}\text { End } \\
\text { span }\end{array}$ & $\begin{array}{l}\text { Middle } \\
\text { span }\end{array}$ & $\begin{array}{l}\text { End } \\
\text { span }\end{array}$ & $\begin{array}{l}\text { Middle } \\
\text { span }\end{array}$ & $\begin{array}{l}\text { End } \\
\text { span }\end{array}$ & $\begin{array}{l}\text { Middle } \\
\text { span }\end{array}$ \\
\hline S-3-03 & 3 & \multirow{3}{*}{2.00} & 3.49 & 3.92 & \multirow{3}{*}{3.18} & \multirow{3}{*}{5.13} & 0.91 & 1.31 \\
\hline S-3-02 & 2 & & 3.58 & 4.22 & & & 0.89 & 1.22 \\
\hline S-3-01 & 1 & & 3.78 & 4.49 & & & 0.84 & 1.14 \\
\hline \multicolumn{7}{|c|}{ Mean } & 0.88 & 1.22 \\
\hline
\end{tabular}

${ }^{*}$ Excluding deflections due to panel self-weight

** Based on fundamental exact solutions in Stamm and Witte [6].

An analysis of the post-elastic response, the failure modes and the corresponding resistances is intentionally omitted since the focus of this paper is on the stress distribution and the elastic phase of the response up to the maximum working load.

There is good agreement between the test data and the results based on the developed design method and the resulting mathematical model. The stiffness overestimation for the central span is not critical since the end spans dominate the design in terms of deflections. It may, therefore, be concluded that the developed exact analytical solutions presented in Section 5 provide safe 
and reliable results and are suitable for the working load (SLS) design checks of multi-span profiled sandwich panels under uniformly distributed load.

\section{Numerical examples for typical cases}

The design method developed for triple-span sandwich panels presented in Section 5 was used to calculate numerical examples for typical cases. A typical panel case of varying core depth was chosen, comprising identical nominal geometrical and material properties to those used for the experimental programme (Figure 3).

A multi-span arrangement with equal spans of $1.8 \mathrm{~m}$ was selected. The span is representative of typical purlin support spacing for portal frame construction, which attracts a significant proportion of the roof sandwich panel production. A uniform distributed load of $1 \mathrm{kN} / \mathrm{m}$ was chosen to act on the panel. The cross section had the following properties: $A_{F 1}=494.7 \mathrm{~mm}^{2}$, $A_{F 2}=309.7 \mathrm{~mm}^{2}, I_{F 1}=52,944 \mathrm{~mm}^{4}, I_{F 2}=494.1 \mathrm{~mm}^{4}, d_{2}=31.3 \mathrm{~mm}, d_{11}=24.6 \mathrm{~mm}, d_{21}=0.96 \mathrm{~mm}$. The distribution of bending moments in the 'flange' and 'sandwich' part and the stresses in the outer and inner sheets at the intermediate supports are shown in Table 9 for calculations based on:

- Approximate graphical solutions according to Berner [5] and Heywood et. al. [4]

- Exact analytical solutions for continuous double-span arrangement according to ECCS Recommendations [1]

- Newly developed exact analytical solutions for continuous triple-span arrangements presented in the current paper.

The ratios of the results between the approximate and exact solution are shown in Table 10 . 
Table 9 Comparison between approximate and exact solutions for bending moments and stresses at supports

\begin{tabular}{|c|c|c|c|c|c|c|c|c|c|c|c|c|}
\hline \multirow[t]{2}{*}{$\begin{array}{l}\text { Core } \\
\text { depth }\end{array}$} & \multicolumn{4}{|c|}{$\begin{array}{l}\text { Approximate graphical } \\
\text { solution* }\end{array}$} & \multicolumn{4}{|c|}{$\begin{array}{l}\text { Exact analytical solution for } \\
\text { double-span** }\end{array}$} & \multicolumn{4}{|c|}{$\begin{array}{l}\text { Exact analytical solution (new } \\
\text { guidance) }\end{array}$} \\
\hline & $\mathrm{M}_{\mathrm{D}}$ & $\mathrm{M}_{\mathrm{S}}$ & $\sigma_{\mathrm{F} 1}$ & $\sigma_{\mathrm{F} 2}$ & $\mathrm{M}_{\mathrm{D}}$ & $\mathrm{M}_{\mathrm{S}}$ & $\sigma_{\mathrm{F} 1}$ & $\sigma_{\mathrm{F} 2}$ & $\mathrm{M}_{\mathrm{D}}$ & $\mathrm{M}_{\mathrm{S}}$ & $\sigma_{\mathrm{F} 1}$ & $\sigma_{\mathrm{F} 2}$ \\
\hline $\mathrm{mm}$ & \multicolumn{2}{|c|}{$\mathrm{kNm}$} & \multicolumn{2}{|c|}{$\mathrm{N} / \mathrm{mm}^{2}$} & \multicolumn{2}{|c|}{$\mathrm{kNm}$} & \multicolumn{2}{|c|}{$\mathrm{N} / \mathrm{mm}^{2}$} & \multicolumn{2}{|c|}{$\mathrm{kNm}$} & \multicolumn{2}{|c|}{$\mathrm{N} / \mathrm{mm}^{2}$} \\
\hline 60 & -0.214 & -0.139 & 105.9 & 6.7 & -0.198 & -0.111 & 97.6 & 5.3 & -0.179 & -0.108 & 88.3 & 5.2 \\
\hline 80 & -0.207 & -0.135 & 101.3 & 5.0 & -0.178 & -0.106 & 87.1 & 3.9 & -0.163 & -0.111 & 80.0 & 4.1 \\
\hline 100 & -0.209 & -0.123 & 101.7 & 3.7 & -0.163 & -0.100 & 79.3 & 3.0 & -0.151 & -0.111 & 73.7 & 3.3 \\
\hline 120 & -0.210 & -0.108 & 101.7 & 2.8 & -0.151 & -0.094 & 73.2 & 2.4 & -0.141 & -0.109 & 68.7 & 2.8 \\
\hline 130 & -0.210 & -0.102 & 101.2 & 2.4 & -0.146 & -0.091 & 70.6 & 2.1 & -0.137 & -0.108 & 66.5 & 2.5 \\
\hline
\end{tabular}

${ }^{*}$ For core depth $60 \mathrm{~mm}$ according to Berner [5]; for deeper cores according to Heywood et. al. [4]

${ }^{* *}$ According to ECCS Recommendations [1]

Table 10 Ratios between approximate and exact results for bending moments and stresses at supports

\begin{tabular}{|l|l|l|l|l|l|l|l|l|}
\hline $\begin{array}{l}\text { Core } \\
\text { depth } \\
(\mathbf{m m})\end{array}$ & \multicolumn{4}{l}{$\begin{array}{l}\text { Ratio - } \\
\text { Exact analytical solution (new guidance): } \\
\text { Approximate graphical solution* }\end{array}$} & \multicolumn{3}{l|}{$\begin{array}{l}\text { Ratio - } \\
\text { Exact analytical solution (new guidance): } \\
\text { Exact analytical solution for double span** }\end{array}$} \\
\cline { 2 - 10 } & $\mathrm{M}_{\mathrm{D}}$ & $\mathrm{M}_{\mathrm{S}}$ & $\sigma_{\mathrm{F} 1}$ & $\sigma_{\mathrm{F} 2}$ & $\mathrm{M}_{\mathrm{D}}$ & $\mathrm{M}_{\mathrm{S}}$ & $\sigma_{\mathrm{F} 1}$ & $\sigma_{\mathrm{F} 2}$ \\
\hline $\mathbf{6 0}$ & 0.84 & 0.78 & 0.83 & 0.78 & 0.90 & 0.97 & 0.90 & 0.98 \\
\hline $\mathbf{8 0}$ & 0.79 & 0.82 & 0.79 & 0.82 & 0.92 & 1.05 & 0.92 & 1.05 \\
\hline $\mathbf{1 0 0}$ & 0.72 & 0.90 & 0.72 & 0.90 & 0.93 & 1.11 & 0.93 & 1.11 \\
\hline $\mathbf{1 2 0}$ & 0.67 & 1.00 & 0.68 & 1.00 & 0.93 & 1.16 & 0.94 & 1.16 \\
\hline $\mathbf{1 3 0}$ & 0.65 & 1.06 & 0.66 & 1.06 & 0.94 & 1.19 & 0.94 & 1.19 \\
\hline
\end{tabular}

*For core depth 60mm according to Berner [5]; for deeper cores according to Heywood et. al. [4]

**According to ECCS Recommendations [1]

The results show that the new guidance leads to lower bending moments in the 'flange' part when compared to both approximate graphical solutions and exact analytical solutions for the double-span case. The bending moments developed in the 'sandwich' part are slightly higher compared to the earlier methods, however this has a relieving effect on the stresses developed in the full profiles (i.e. the outer face). As shown during testing, the stresses developed in the outer skin are typically the critical ones.

The comparison shows that for typical panel and continuous span arrangements, a significant reduction of calculated stresses up to $35 \%$ can be achieved compared with previous approximate methods, and up to $10 \%$ for double-span solutions. 


\section{Concluding remarks}

Whilst exact analytical solutions are available for single- and double- span arrangements with equal spans under distributed load, there is a lack of guidance for multi- span cases. Current approximate solutions yield conservative results and often fall out of the range of insulation thickness specifications for modern sandwich panels.

The paper presents newly developed analytical solutions for triple-span arrangements of sandwich panels with fully profiled faces in flexure. Triple-span arrangements are sufficiently representative of multi-span for design purposes. The derivation of the solutions is based on a set of fundamental equations for single span panels under uniformly distributed and point loads, which were previously derived directly from the governing differential equations for sandwich beams. Hence, the developed solutions are exact. The new method considers the stiffness and stress distribution in the elastic stage and is particularly useful for the estimation of the maximum working load which typically dominates design. The new design method allows for the design of profiled sandwich panels of any geometry and material assembly and is simple to implement in any widely available mathematical or spreadsheet software application.

A set of specifically designed tests of single- and triple-span panels with steel profiled faces and PIR cores were undertaken. These facilitated investigation of the response in the elastic and post-elastic stages with regard to stiffness, failure modes, reserve of strength and propagation to global collapse. Test results were used to assess the reliability of the mathematical solutions which form the basis of the new design method and a high level of agreement was demonstrated in terms of stiffness and prediction of maximum elastic load. It may therefore be concluded that the developed analytical solutions provide safe and reliable results and can be used for the elastic design and calculation of maximum working load for multi-span profiled sandwich panels under uniformly distributed load. 
A comparison of the results offered by the new guidance against those of derived from earlier literature demonstrated that the degree of conservatism previously applied is no longer necessary. The mathematical solutions were proven to be safe. The design method facilitates production of reliable and less conservative load versus equal-span tables, which are typically presented in the manufacturers' literature, without the need for the use of specialist software, such as finite element analysis, and associated knowledge. The new solutions do not conflict with the basis of the design standard EN 14509:2013 [9] and may, therefore, be used in practical design applications.

Finally, a significant reserve of strength and rotational capacity was noticed during the testing of the continuous arrangements after the initial failure, indicating a reasonable level of residual bending resistance at the intermediate support. Exploitation of the remaining bending resistance could be particularly beneficial for plastic design at ULS and form part of the authors' on-going research.

Use of the approach for the design of multi-span arrangements would lead to the elimination of a significant amount of conservatism compared to current design methods and consequent improved structural efficiency in terms of increased panel spans, wider secondary beam spacing and lighter panel specifications (thinner steel and insulation where allowed). The consequential material economy may lead to considerable savings in terms of fabrication and installation costs, as well as embodied carbon.

\section{Acknowledgments}

The authors would like to thank: Mr. Ray Salter, Laboratory Manager at Oxford Brookes University, for his valuable help throughout the testing procedure, the Engineering and Physical Sciences Research Council (EPSRC) and TATA Steel Colors for financially supporting the research project. 


\section{References}

[1] ECCS TWG 7.9 \& CIB W056 (2000) European Recommendations for sandwich panels -

Part 1: Design. CIB Publication 257. CIB/ECCS, Rotterdam/Brussels.

[2] Davies, J. M. (1986) The analysis of sandwich panels with profiled faces. 8th International Speciality Conference on Cold-Formed Steel Structures, St Louis, Missouri, November 11-12, pp. 351-369.

[3] Davies, J. M. (2013) Thermal Elongation of Sandwich Panels. Proceedings of the ICE Structures and Buildings. Volume 166, Issue SB3, pp. 125-138. DOI: 10.1680/stbu.11.00017

[4] Heywood, M., Ogden, R., Moutaftsis, D. (2014) Profiled sandwich panels with deep foam cores in flexure. Proceedings of the ICE - Construction Materials, Volume 167, Issue 1, pp. 42 56. DOI: $10.1680 /$ coma. 12.00016

[5] Berner, K. (1998) Praxisgerechte Nachweise zur Trag- und Gebrauchsfähigkeit von Sandwichbauteilen (Practical design checks for sandwich panels at the ultimate and serviceability limit states), Stahlbau 67, vol. 12, pp. 910-925.

[6] Stamm, K. and Witte, H. (1974) Sandwichkonstruktionen - Berechnung, Fertigung, Ausführung (Sandwich Construction - Calculation, Manufacture and Use), Springer-Verlag, Wien and New York.

[7] Allen, H. G. (1969) Analysis and Design of Structural Sandwich Panels. Pergamon Press, Oxford, UK.

[8] Davies, J. M. (ed.) (2001) Lightweight Sandwich Construction. Blackwell Science, published on behalf of the CIB commission, W056 Sandwich Panels (joint CIB-ECCS commission), Chichester, UK. 
[9] CEN - European Committee for Standardization (2013) EN 14509:2013: Self-supporting double skin metal faced insulating panels - Factory made products - Specifications. CEN, Brussels, Belgium.

[10] CEN - European Committee for Standardization (2007) EN 14509:2006: Self-supporting double skin metal faced insulating panels - Factory made products - Specifications. CEN, Brussels, Belgium.

[11] Gosowski, B., Gosowski M. (2012) Distributional solutions of bending problems for continuous sandwich panels with thin facings. Archives of Civil and Mechanical Engineering, Volume 12, pp. 13-22. DOI: 10.1016/j.acme.2012.03.003

[12] Gosowski, B, Gosowski M. (2014) Exact solution of bending problem for continuous sandwich panels with profiled facings. Journal of Constructional Steel Research, Volume 101, pp. 53-60. DOI: $10.1016 /$ j.jcsr.2014.04.033

[13] Hassinen P., Martikainen L. (1994) Analysis and Design of Continuous Sandwich Panels. $12^{\text {th }}$ International Speciality Conference on Cold-formed Steel Structures. St. Louis, Missouri, USA, October 18-19, pp. 523-538.

[14] Hassinen P., Martikainen L. (1996) Design Models of Continuous Sandwich Panels. 13 ${ }^{\text {th }}$ International Speciality Conference on Cold-formed Steel Structures. St. Louis, Missouri, USA, October 17-18, pp. 293-307. 